Indian J. Anim. HIth. (2019), 58(2) : 236-238

DOI: https://doi.org/10.36062/ijah.58.2.2019.236-238

Short Communication

\title{
PREGNANCY TOXAEMIA IN AN ASSAM HILL GOAT: ITS DIAGNOSIS AND SUCCESSFUL MANAGEMENT
}

\author{
N. AHMED*, M. P. BAISHYA, S. N. YADAV \\ P. K. BORO, J. M. DAS AND A. DAS \\ Veterinary Clinical Complex \\ Lakhimpur College of Veterinary Science \\ Assam Agricultural University, North Lakhimpur \\ Joyhing - 787 051, Assam, India
}

\begin{abstract}
A two year old Assam Hill goat was presented with the history of continuous straining efforts and neurological signs from last two days before reporting. Based on serum profile and radiography, it was confirmed as pregnancy toxaemia. This paper describes diagnosis and successful surgical management of pregnancy toxaemia complicated with rectal and vaginal prolapse in an Assam Hill goat. The goat recovered uneventfully.
\end{abstract}

Key words: Assam Hill goat, Caesarean section, Pregnancy toxaemia

Pregnancy toxaemia or ketosis is a metabolic disorder of small ruminants occurs at the final stage of gestation due to abnormal metabolism of carbohydrates and fats; which is characterized by hypoglycemia and hyperketonemia. The occurrence of this disorder may be either due to poor nutrition or excessive demand from multiple rapidly growing fetuses but sometimes both contributed together (Lima et al., 2012). Pregnancy toxaemia in small ruminant is characterized by inappetence and neurological signs leading to comatose stage and finally death (Kahn and Line, 2005). This manuscript describes the clinical approach in proper diagnosis and its successful management of pregnancy toxaemia in an Assam Hill goat.

A two year old Assam Hill goat in first parity and last stage of gestation was presented in the Veterinary Clinical Complex, Lakhimpur College of Veterinary Science, Assam Agricultural University, Joyhing, North Lakhimpur, Assam, India with the history of continuous straining efforts, inappetance, head pressing against wall, dilated pupil, staggering gait and teeth grinding from last two days before reporting. The goat also had rectal and vaginal prolapse. Details clinical examination revealed the goat was obese, normal body temperature, increased respiration and increased pulse rate. Blood was collected for

*Corresponding Author 


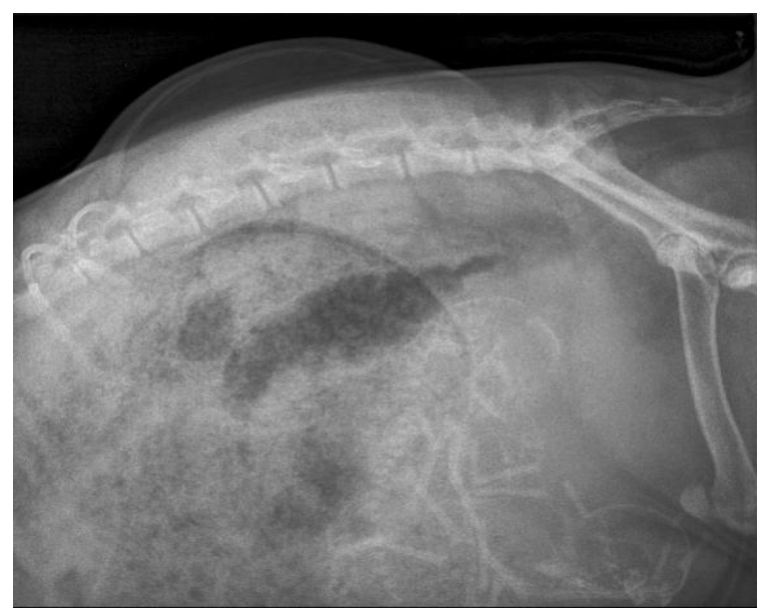

Fig. 1. Radiographic image of twin fetus

laboratory examination which showed serum glucose level as $35.44 \mathrm{mg} \%$ and ketone 1.2 $\mathrm{mmol} / \mathrm{L}$. On radiography, it was confirmed that the goat had twin fetus (Fig. 1). Based on clinical observation, serum profile and radiology, the case was diagnosed as pregnancy toxaemia. Further, ultrasonography was performed and it was confirmed that the fetuses were dead.

In the present case, manual obstetrical operations for vaginal delivery of the dead fetuses could not be performed due to closed cervix. Hence for immediate relief and to save the life of the dam, caesarean section was performed at the left paralumbar fossa in right lateral recumbency by left ventro-lateral laparotomy. The operation was carried out under the anaesthetic mixture of xylazine and ketamine @ 0.02 and $10 \mathrm{mg} / \mathrm{kg}$ b. wt. i.v. respectively. The operation site was desensitized by inverted "L" block with $2 \%$ lignocaine hydrochloride. On caesarean section two dead premature fetuses were delivered. The prolapsed parts were cleaned with normal saline solution (NSS), then replaced manually and retention suture was applied.
The goat was treated with $20 \%$ dextrose normal saline (DNS, $500 \mathrm{~mL}$ i.v.) twice daily, ceftriaxone $(20 \mathrm{mg} / \mathrm{kg} \mathrm{b}$. wt i.v.), flunixin meglumine (2 $\mathrm{mg} / \mathrm{kg}$ b.wt. i.m.), (chlorpheniramine maleate $(20 \mathrm{mg}$ i.m.), dexamethasone (4.4 mg i.m) and vitamin-B complex for five consecutive days. After 72 hours of surgery and treatment revealed normal respiration rate, normal pulse rate, blood ketone $(0.36 \mathrm{mmol} / \mathrm{L})$ and serum glucose $(43 \mathrm{mg} \%)$. The suture was removed after $10^{\text {th }}$ day of surgery. The goat had an uneventful recovery.

Pregnancy toxaemia is generally observed in under nourished animals, however in the present case, the affected goat was in over condition as obese does carrying multiple fetuses are at higher risk because of the limited rumen space for adequate intake of feed (Jones and Navarre, 2014) due to excessive fat accumulation in the abdominal cavity. In the present case, reduction in serum glucose level could be attributed to higher demand of glucose by the developing fetuses (Yadav et al., 2018).

Similar with the present case, early researchers suggest caesarean section in goat in advanced 
stages of pregnancy toxaemia or in heavily pregnant doe that do not respond well to treatment of glucose (Manokaran et al., 2011; Abba et al., 2015). In the present case, the affected goat was treated with DNS to replace the glucose and electrolyte loss as well as to flash out the ketone bodies, which was in agreement with the findings of others (Quadir et al., 2017).

\section{REFERENCES}

Abba Y, Abdullah FFA, Chung ELT, Sadiq MA, Mohammed K et al., 2015. Biochemical and pathological findings of pregnancy toxaemia in Saanen doe: A case report. J Adv Vet Anim Res, 2: 236-239

Jones M and Navarre C, 2014. Fluid therapy in small ruminants and camelids. Vet Clinic Food Anim, 30: 441-453

Kahn CM and Line S, 2005. The Merck Veterinary Manual. $9^{\text {th }}$ Edn., USA, Merial

Manokaran S, Ravikumar K, Palanisamy M, Raguvaran R and Mohanasundaram N, 2011. Pregnancy toxaemia and hypocalcaemia in a Jamnapari doe. Indian J Small Ruminants, 17(2): $250-251$
Pregnancy toxaemia is a life threatening metabolic disease in goats causing economic loss to farmers. We suggest proper nutritional management of goats during gestation as under and over body nourishment may lead to occurrence of this metabolic disease.

Conflict of interest: The authors declare that they have no competing interests.

Lima MS, Pascoal RA, Stilwell GT and Hjerpe CA, 2012. Clinical findings, blood chemistry values and epidemiologic data from dairy goats with pregnancy toxemia. Bov Practitioner, 46: 102-110

Quadir A, Islam ST, Bhat IA, Khan M, Dar PS et al., 2017. Clinical case of pregnancy toxaemia and its therapeutic management in a she goat: A case study. The Pharma Innovation J, 6: 179-182

Yadav SN, Kalita DN, Phukan A, Das BC, Dutta TC et al., 2018. Biochemical and hematological studies of sub-clinical ketosis in goat. Int J Chemi Studies, 6: 16-18 